\title{
Supervisie in de medische praktijk: het oordeel van specialisten in opleiding. Arts-assistenten kindergeneeskunde beoordelen supervisoren*
}

\author{
J.O. Busari, P.M. Greidanus, N.M. Weggelaar, I.A.M. Schiering
}

\section{Samenvatting}

Inleiding: De begeleiding van arts-assistenten in opleiding tot medische specialist (aios) valt onder de verantwoordelijkheid van medisch specialisten. Veel van hen zijn echter niet bekend met de principes van het geven van gestructureerde supervisie en onderwijs. Dit is opvallend, omdat het behoort tot een van de voornaamste taken van klinische docenten. Hoewel supervisie veelal niet op gestructureerde basis plaatsvindt, is gebleken dat de begeleiding door de medische staf een essentieel onderdeel is van de scholing van de arts-assistent tot medisch specialist. Om een beter inzicht te verkrijgen in de kwaliteit van de supervisie in de praktijk hebben we onderzocht hoe de arts-assistenten de begeleiding ervaren en wat zij beschouwen als goede supervisie of juist onvoldoende begeleiding.

Methode: We hebben twee enquêterondes gehouden onder aios (in 2003 en 2004) op de afdeling kindergeneeskunde van het Emma kinderziekenhuis/AMC. 58 stafleden welke direct betrokken zijn bij de begeleiding van de arts-assistenten werden beoordeeld. Het onderzoek vond plaats op de paediatrische intensive care unit (PICU), de neonatologische intensive care unit (NICU) en op de algemeen pediatrische zorgafdelingen. Erwerden twee verschillende gestandardiseerde vragenlijsten gebruikt om de stafleden van de NICU, PICU en algemene pediatrie te beoordelen.

Resultaten: Over het algemeen werd de kwaliteit van de supervisie door de arts-assistenten als ruim voldoende tot goed beoordeeld. De gemiddelde score van de stafleden op de afdeling algemene pediatrie was 3.57 ( $s d=0.42)$ op een schaal van $1=$ zeer slecht tot $5=$ zeer goed. Op de intensive care-afdelingen waren de scores 7.21 (PICU; sd=0.90) en 7.49 (NICU; sd=0.44) op een schaal van $1=$ zeer slecht tot $10=$ zeer goed. Voor de stafleden van de afdeling algemene pediatrie werd het tot stand brengen van een goede leeromgeving het meest positef gescoord (gemiddeld 4.05; sd=0.46). Besluitvorming op basis van een kosten-batenanalyse werd het laagst gescoord (gemiddeld 2.79; sd=0.36). De begeleiding tijdens het aanleren van nieuwe practische vaardigheden en effectieve communicatie zijn voor de meeste assistenten voor verbetering vatbaar. De resultaten uit 2004 vertonen verder geen significante verschillen met die uit 2003.

Discussie en conclusie: De resultaten laten zien dat in het algemeen de kwaliteit van de supervisie, zoals deze wordt geboden door medisch specialisten, positief gewaardeerd wordt. De arts-assistenten willen graag supervisie van betrokken, coöperatieve en begripvolle dokters. Ze geven er de voorkeur aan om als volwassen leerlingen te worden gezien en waarderen feedback wanneer deze constructief, duidelijk en relevant voor de opleiding is. Alhoewel op bepaalde aspecten van supervisie enige verbetering gezien wordt, zijn de verschillen ten opzichte van 2003 niet significant. De kwaliteit van de supervisie van aios kan dus nog altijd verbeterd worden. (Busari JO, Greidanus PM, Weggelaar NM, Schiering IAM. Supervisie in de medische praktijk: het oordeel van specialisten in opleiding. Arts-assistenten kindergeneeskunde beoordelen supervisoren. Tijdschrift voor Medisch Onderwijs 2006;25(4):170-179.)

\footnotetext{
Dit onderzoek werd deels eerder gepubliceerd in het tijdschrift Medical Education: Busari JO, Weggelaar NM, Knottnerus AC, Greidanus PM, Scherpbier AJJA. How medical residents perceive the quality of supervision provided by attending doctors in the clinical setting. Med Educ 2005;39:696-703.
} 


\section{Inleiding}

In academische ziekenhuizen is het lesgeven aan arts-assistenten in opleiding (aios) primair een verantwoordelijkheid van medisch specialisten. In de praktijk blijkt dat de meerderheid van hen niet voldoende op de hoogte is van de principes van medische onderwijskunde en de didactische vaardigheden die nodig zijn voor deze functie.1-3 Stafleden geven zowel medisch studenten als arts-assistenten onderwijs en supervisie, terwijl een groot deel van hen nooit enige training hierin heeft gekregen. De meeste didactische vaardigheden die zij gebruiken, zijn gebaseerd op hun eigen ervaring, verkregen door observatie van onder meer rolmodellen en door 'trial and error' ${ }^{4}$ Als gevolg hiervan is het bereiken en handhaven van de benodigde kwaliteit van klinische supervisie (en onderwijs) in de medische opleiding moeilijk te garanderen.

In de medisch onderwijskundige literatuur beschreven Kilminster en Jolly klinische supervisie als een complexe activiteit die optreedt in diverse contexten en die verschillende functies heeft. Deze complexiteit verklaart waarschijnlijk waarom het zo moeilijk is om supervisie te definieren en waarom er meer onderzoek verricht dient te worden om de kwaliteit van supervisie te verbeteren. 5

Een duidelijke structuur in de supervisie van arts-assistenten en richtlijnen om inadequate supervisie te voorkomen, blijken onmisbaar te zijn. ${ }^{6-7}$ Terwijl arts-assistenten frequent hun onvrede uiten over de kwaliteit van de genoten supervisie, is deze supervisie essentieel gebleken voor hun professionele ontwikkeling. ${ }^{8-9}$ De veronderstelling dat alleen vakkennis voldoende is om medisch studenten of artsassistenten te onderwijzen, is niet langer verdedigbaar. Onderwijs en klinische supervisie zijn een beroepsmatige verantwoordelijkheid van medisch specialisten en er is een toenemende behoefte aan onderwijstrainingsprogramma's om onderwijsvaardigheden te verbeteren. ${ }^{10-13}$

De meeste onderzoekers zijn het er over eens dat het doel van supervisie in grote lijnen is: educatie, motivatie en leren organiseren. Daarnaast dient het de professionele ontwikkeling van specialisten (in opleiding) te bevorderen en adequate zorg voor de patiënt te waarborgen. ${ }^{7,14}$ Toch is er, ondanks de beschikbare informatie over dit onderwerp, een onvoldoende theoretische basis voor de huidige wijze van supervisie in de medische praktijk. Onduidelijke theoretische verwijzingen en problemen met een goede onderzoeksopzet worden genoemd als enkele oorzaken van de tekortkomingen van diverse studies die de verschillende aspecten van klinische supervisie onderzoeken. Helaas ondermijnen deze inconsistenties de bevindingen van zulke studies. Om een antwoord te vinden op de vraag welke facetten van de supervisie in de kliniek verbetering behoeven, is er meer gestructureerd en methodisch correct uitgevoerd onderzoek noodzakelijk. ${ }^{5}$ Het doel van onze studie was om de kwaliteit van de supervisie, gegeven door stafleden aan arts-assistenten, te onderzoeken, onder meer door:

1. te inventariseren wat arts-assistenten verstaan onder slechte supervisie;

2. te inventariseren welke aspecten van slechte supervisie verbetering behoeven;

3. die aspecten van supervisie te identificeren die kenmerkend zijn voor een goede supervisie.

\section{Methode}

\section{Subjecten}

Het onderzoek werd in 2003 en 2004 gedaan in het Emma Kinderziekenhuis (EKZ), onderdeel van het Academisch Medisch Centrum te Amsterdam. De bij 
het onderzoek betrokken afdelingen waar supervisie van arts-assistenten door specialisten plaatsvond, waren de algemene pediatrie (AP), de pediatrische intensive care unit (PICU) en de neonatale intensive care unit (NICU). Om de kwaliteit van de door specialisten gegeven supervisie zo goed mogelijk te kunnen onderzoeken, werden de specialisten beoordeeld door zoveel mogelijk verschillende arts-assistenten. Tevens werd onderzocht welke afzonderlijke onderdelen van supervisie de beste voorspellers waren van supervisie in het algemeen, en werden de gegevens van de twee opeenvolgende jaren met elkaar vergeleken om een uitspraak te kunnen doen over de consistentie van de kwaliteit van de supervisie in het EKZ. Omdat we (kwaliteit van) supervisie op een positieve manier onder de aandacht wilden brengen, is gekozen voor het uitreiken van een prijs aan de beste supervisor per afdeling.

Alleen specialisten die direct betrokken waren bij de supervisie van arts-assistenten overdag of tijdens nachtdiensten op de afdelingen en/of polikliniek werden beoordeeld. Alle arts-assistenten in het EKZ $(n=38)$, in verschillende fasen van hun opleiding, hebben specialisten beoordeeld op de kwaliteit van gegeven supervisie. Vooraf is met alle deelnemers het doel en de opzet van de studie besproken. Er is benadrukt dat alle beoordelingen anoniem zouden plaatsvinden. Elke arts-assistent kon zoveel stafleden beoordelen als hij/zij wenste, waarbij hij/zij bij voorkeur gedurende een langere periode onder supervisie van deze persoon had gestaan. De stafleden wisten niet wanneer hun individuele beoordelingen plaatsvonden.

\section{Instrumenten}

In deze studie is gebruikt gemaakt van twee verschillende beoordelingsformulieren. We hebben dit gedaan, omdat er door de arts-assistenten een verschil be- merkt werd in de manier van superviseren op de IC-units en de AP-afdelingen. Voor de start van het onderzoek bleek middels korte interviews onder de arts-assistenten dat men behoorlijk tevreden was over de genoten supervisie op de intensive careafdelingen en veel minder over die op de AP-afdelingen. Wij waren geïnteresseerd in de oorzaak van dit verschil. Met behulp van de uitgebreidere beoordelingsformulieren die we voor de AP-afdelingen hebben gebruikt (zie figuur 1), kon concretere feedback worden gegeven aan supervisoren. De vragenlijst die wij gebruikt hebben om de supervisie op de IC's te beoordelen is de Wisconsin Inventory of Clinical Teaching. ${ }^{15}$ Op een schaal van 1 (zeer slecht) tot 10 (uitmuntend) werden de volgende items met betrekking tot kwaliteit van supervisie gescoord: klinisch rolmodel, professionele mentor, instructeur, evaluator en supervisor. Voor dit onderzoek hebben wij een gemiddelde score van 7 of meer als voldoende beschouwd.

Om de kwaliteit van de supervisie te beoordelen op AP-afdelingen is gebruik gemaakt van de Cleveland Clinic's Teaching Effectiveness Instrument (CCTEI). ${ }^{16}$ Op een Likert-schaal van 1 (nooit/zeer slecht) tot 5 (altijd/zeer goed) werden 15 items gescoord die allen betrekking hebben op kwaliteiten die een goede supervisor zou moeten hebben. Met behulp van deze uitgebreidere beoordelingsformulieren kon concretere feedback worden gegeven aan supervisoren. Een gemiddelde score van 3 of meer werd beschouwd als voldoende. Uit de studie van Copeland en Hewson blijkt dat per beoordeelde persoon een minimum van vijf beoordelingen nodig is om een betrouwbare beoordeling te verkrijgen. ${ }^{16}$ Ten slotte werd de assistenten de gelegenheid geboden om aanvullend commentaar te leveren om zo de beoordeling te onderbouwen. 


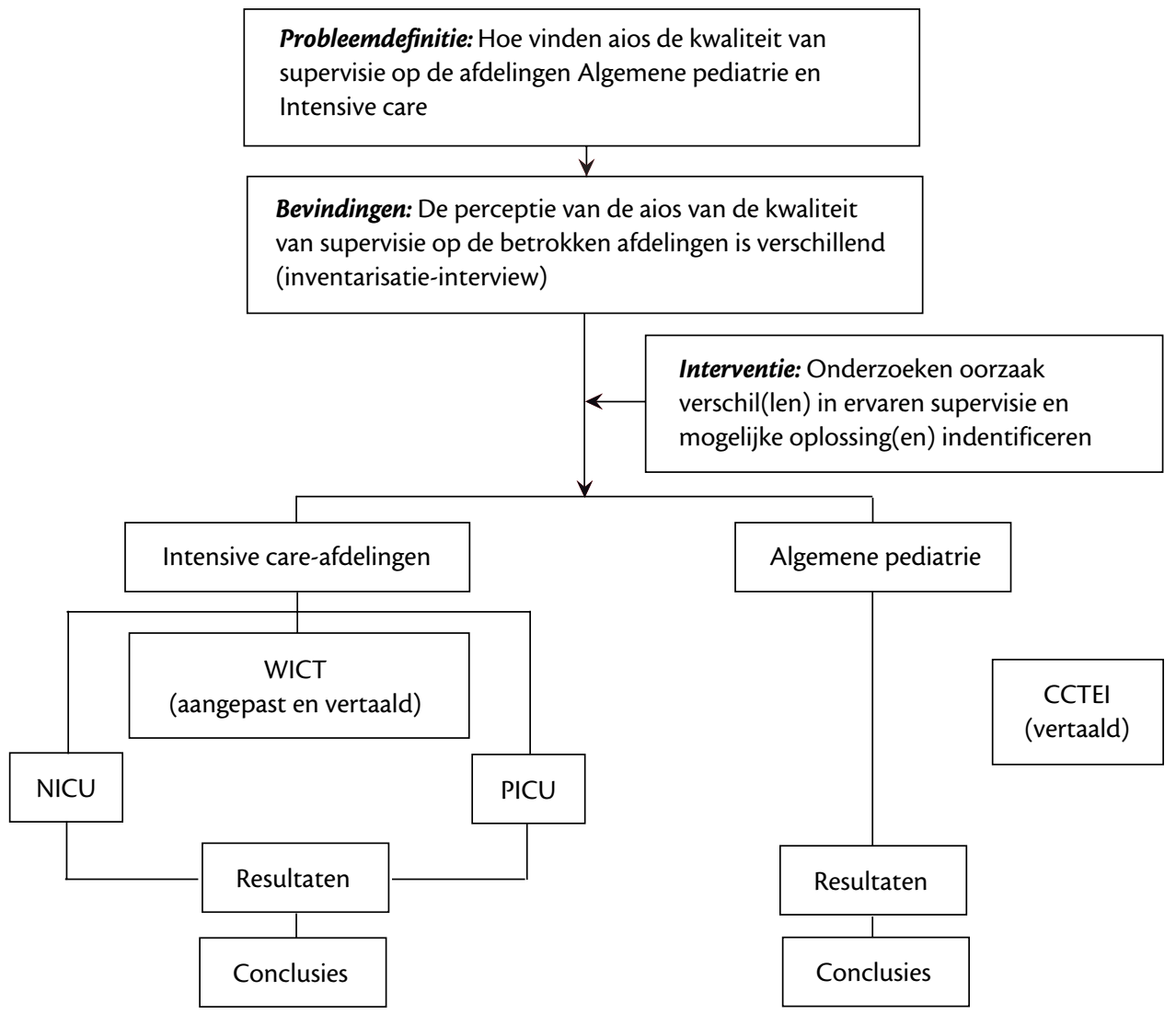

Figuur 1. Flow-chart: beslisvorming ten aanzien van de keuze voor vragenlijsten.

\section{Statistische analyse}

Het gemiddelde en de standaarddeviatie werden berekend voor de verschillende items van beide lijsten. Met behulp van de Spearman rho-rank order werd onderzocht welke items de beste voorspellers waren voor supervisie in het algemeen en per individu. Door middel van multiple regressie-analyse werden die items uitgelicht die het beste correleerden met de kwaliteit van supervisie van de groep als geheel.

\section{Resultaten}

De stafleden werden beoordeeld door 38 arts-assistenten in verschillende stadia van hun opleiding tot kinderarts. Van de 48 stafleden in 2003 waren er 20 intensive care-specialisten (NICU 11 en PICU 9). De overige stafleden (28) waren algemeen kinderarts (AP) of subspecialist. In 2004 werden 58 stafleden (PICU 10, NICU 14 en AP 34) beoordeeld. Ieder staflid werd beoordeeld door minimaal vijf arts-assistenten. In 2003 en 2004 werden respectievelijk 284 (PICU 54, NICU 66 en AP 148) en 287 (PICU 51, NICU 62 en AP 174) beoordelingsformulieren ingeleverd. Wij hebben de resultaten van beide jaren met elkaar vergeleken en het gemiddelde hiervan weergegeven in tabel 1. 
Tabel 1. Perceptie van arts-assistenten op de supervisie gegeven door stafleden op de intensive care afdelingen (combinatie van de gegevens van 2003 en 2004).

\begin{tabular}{|c|c|c|c|c|c|c|c|c|c|}
\hline \multirow[t]{2}{*}{ Supervisie rol } & \multicolumn{3}{|c|}{$\operatorname{NICU}(n=14)^{\gamma}$} & \multicolumn{3}{|c|}{$\operatorname{PICU}(n=10)^{\gamma}$} & \multicolumn{3}{|c|}{$\begin{array}{l}\text { Intensive care-afdelingen } \\
\text { (gecombineerd) }\end{array}$} \\
\hline & Mean & sd & Range & Mean & sd & Range & Mean & sd & $\mathrm{Cl} 95 \%$ \\
\hline Klinisch rolmodel & 7.46 & 0.63 & 2.41 & 7.38 & 0.99 & 3.55 & 7.43 & 0.78 & $7.09-7.75$ \\
\hline Professionele mentor* & 7.59 & 0.50 & 1.65 & 7.19 & 0.96 & 3.30 & 7.42 & 0.74 & $7.07-7.57$ \\
\hline Instructor* & 7.42 & 0.44 & 1.73 & 7.27 & 0.92 & 2.98 & 7.36 & 0.67 & $7.11-7.73$ \\
\hline Evaluator & 7.47 & 0.43 & 1.50 & 7.10 & 0.74 & 2.34 & 7.32 & 0.60 & $7.06-7.65$ \\
\hline Supervisor & 7.53 & 0.40 & 1.25 & 7.11 & 0.95 & 3.18 & 7.35 & 0.70 & $7.08-7.64$ \\
\hline Supervisie in het algemeen & 7.49 & 0.44 & 1.48 & 7.21 & 0.90 & 3.06 & 7.37 & 0.67 & $7.09-7.66$ \\
\hline
\end{tabular}

\section{Kwaliteit van supervisie op de IC's}

Over het algemeen is de kwaliteit van supervisie op de NICU en PICU goed te noemen en redelijk consistent over beide jaren. De totaalscores van de groepen waren in 2003: PICU gemiddeld 7,36 (sd=0,69) en NICU gemiddeld 7,41 (sd=0,58). In 2004 was dit respectievelijk een gemiddelde van $7,40(s d=0,87)$ en $7,70(s d=0,42)$. Voor een weergave van de mean scores op de verschillende items van supervisie en de totaalscores van supervisie per IC: zie tabel 1. De artsen van de PICU scoorden het hoogst in hun rol als 'klinischrol model' en het laagst als 'evaluator'. Door de NICU werd het beste gescoord op 'professionele mentor' en het minste op 'instructor'. Alle items die gescoord werden als onderdeel van de totale beoordeling van de kwaliteit van supervisie toonden (met behulp van de Spearman's rank order-analyse) een positieve correlatie met supervisie in het algemeen. Multiple regressie-analyse liet zien dat de rollen van 'professioneel mentor' en 'instructeur' de beste voorspellers zijn van goede supervisie. Er waren geen significante verschillen in scores voor wat betreft geslacht of afdeling.

\section{Kwaliteit van supervisie op de algemene pediatrische afdelingen/polikliniek}

Arts-assistenten waren over het algemeen tevreden over de genoten supervisie. De resultaten van beide jaren lieten zien dat de kwaliteit van de supervisie constant was (2003: gemiddeld 3,58; sd $=0,44$ en 2004: gemiddeld 3,57; $\mathrm{sd}=0,42$ ). Het hoogst werd er gescoord op het item 'brengt een goede leeromgeving tot stand'. Het minst tevreden waren de arts-assistenten over de aandacht die door supervisoren werd besteed aan de afstemming van zorg en kosten, het leren van communicatieve vaardigheden en het geven van begeleiding bij de uitvoering van vaardigheden. Alle afzonderlijke items van het beoordelingsformulier toonden een significante correlatie met supervisie in het algemeen. De beste voorspellers voor goede supervisie waren de items 'past het onderwijs aan mijn behoefte aan (ervaring, kundigheid enz.)' en 'stimuleert mij om zelfstandig te leren'. Ook hier werd geen significant verschil gevonden tussen mannelijke of vrouwelijke supervisoren (tabel 2). 
Tabel 2. Perceptie van arts-assistenten op de supervisie op de afdeling Algemene Kindergeneeskunde (gegevens van 2003 en 2004 gecombineerd; $n=28 \gamma$ ).

\section{Supervisierol}

1. Brengt een goede leeromgeving tot stand (is toegankelijk, niet bedreigend, enthousiast, et cetera)

2. Laat mij zelfstandig werken naar gelang mijn ervaring en kundigheid

3. Stimuleert mij om zelfstandig te leren*

4. Geeft duidelijke verklaring/uitleg voor zijn/haar beleid en mening

5. Integreert gegevens uit wetenschappelijk onderzoek en/of praktijkstandaarden

6. Stelt vragen die het leren stimuleren

7. Past het onderwijs aan mijn behoeften aan (ervaring, kundigheid, interesse, et cetera)*

8. Geeft regelmatig feedback (zowel positief als negatief)

9. Geeft duidelijk aan wat ik word geacht te weten/doen tijdens deze stage/dienst

10. Onderwijst diagnostische vaardigheden (klinisch redeneren, keuze/interpretatie van aanvullend onderzoek, et cetera)

11. Deelt zijn/haar werktijd zo in dat er ruimte is voor zowel onderwijs als patiëntenzorg

12. Past het onderwijs aan aan de setting waarin het plaatsvindt aan het bed van de patiënt, onderzoekskamer, et cetera)

13. Geeft begeleiding bij de uitvoering van klinische en technische vaardigheden

14. Onderwijst effectieve communicatieve vaardigheden

15. Besteedt aandacht aan de afstemming van zorg en kosten

\section{Supervisie in het algemeen}

$\gamma_{\text {Getallen aangepast voor missing values; }}$

* Beste voorspellers van goede supervisie, gebruik makend van lineaire regressie $\left(\mathrm{R}^{2}=0.97\right)$.

Schaal: $1=$ zeer slecht $/$ nooit; $2=$ slecht/zelden; $3=$ matig/soms; $4=$ goed/vaak; $5=$ zeer goed $/$ altijd.

Alle correlaties tussen supervisie in het algemeen en de verschillende aspecten van supervisie waren significant $(p<.01)$.

\section{Aanvullend commentaar op genoten supervisie}

De door de arts-assistenten gemaakte aanvullende opmerkingen werden verzameld en geanalyseerd door drie onafhankelijk beoordelaars. Hun opmerkingem omtrent de genoten supervisie werden op basis van inhoud geclusteerd en vervolgens ingedeeld in drie categorieën: directe supervisie, klinisch rolmodel en instructie. Gezien het geringe aantal opmerkingen werd geen verdere scheiding gemaakt tussen de NICU, PICU en de AP. Het merendeel van de opmerkingen had ook betrekking op supervisoren van de AP. In de categorie directe supervisie kwam vooral naar voren dat arts-assistenten specialisten prefereren die oprecht geïnteresseerd zijn bij het superviseren, hen behandelen als volwassenen, zelf gemakkelijk te benaderen zijn en die indien nodig bereid zijn assistentie op de afdeling te bieden. Verder werd frequent genoemd dat het als prettig ervaren wordt indien enige mate van zelfstandigheid gestimuleerd wordt. Als negatief commentaar in de categorie directe supervisie kwam naar voren dat sommige supervisoren onvoldoende rekening houden met het niveau/de opleidingsfase van de assistent. Anderen hebben onvoldoende inzicht in de beschikbare tijd voor assistenten om alle klinische taken te volbrengen en bieden te weinig hulp aan in geval van extreme werkdruk. Voor overige opmerkingen zie tabel 3. 
Tabel 3. Enkele commentaren van arts-assistenten op de genoten supervisie (2003 en 2004).

\begin{tabular}{|c|c|c|}
\hline \multirow[t]{3}{*}{$\begin{array}{l}\text { Positief } \\
\text { commentaar }\end{array}$} & Directe supervisie & $\begin{array}{l}\text { - Oprecht geïnteresseerd, makkelijk benaderbaar, helpt daadwerkelijk } \\
\text { op de afdeling. } \\
\text { - Geeft me zelfstandigheid bij het verrichten van mijn taken op de afdeling, } \\
\text { maar is ook altijd beschikbaar bij vragen. } \\
\text { - Geeft me extra onderwijs m.b.t. communicatieve vaardigheden. } \\
\text { - Stuurt me in de beslissing welk aanvullend onderzoek te doen. } \\
\text { - Maakt ondanks drukke werkzaamheden tijd vrij voor overleg. }\end{array}$ \\
\hline & Klinisch rolmodel & $\begin{array}{l}\text { - Enthousiast. } \\
\text { - Schept een ontspannen sfeer die plezierig is en stimuleert tot leren. }\end{array}$ \\
\hline & Instructie & $\begin{array}{l}\text { - Legt veel uit, hetgeen stimulerend is. } \\
\text { - Stelt veel vragen die mij stimuleerden en mijn kennis naar boven haalde. } \\
\text { - De wijze waarop ik werd gestimuleerd om mijn gedachten te uiten } \\
\text { was plezierig. } \\
\text { - Stimuleert en moedigt arts-assistenten aan om regelmatig op het } \\
\text { internet naar literatuur te zoeken. }\end{array}$ \\
\hline \multirow[t]{2}{*}{$\begin{array}{l}\text { Negatief } \\
\text { commentaar }\end{array}$} & Supervisie & $\begin{array}{l}\text { - Reageert soms impulsief, met name als er niet aan de verwachtingen } \\
\text { wordt voldaan. Komt bazig over, is tamelijk ongeduldig. } \\
\text { - Heeft geen idee van de beschikbare tijd voor arts-assistenten om hun } \\
\text { klinische taken te volbrengen, helpt nauwelijks in tijd van nood. } \\
\text { - De gegeven supervisie is onvoldoende voor pas begonnen arts-assistenten. } \\
\text { - Geeft veel kritiek, erkent arts-assistent niet als gelijke. } \\
\text { - Stimuleert geen zelfstandigheid op de afdelingen, neemt teveel werk over. }\end{array}$ \\
\hline & Instructie & $\begin{array}{l}\text { - Mist optimale didactische vaardigheden, maar heeft goede communicatieve } \\
\text { vaardigheden, die hiervoor compenseren. }\end{array}$ \\
\hline
\end{tabular}

\section{Discussie}

Over het algemeen werd de kwaliteit van supervisie, zoals deze wordt geboden op de verschillende afdelingen (NICU, PICU en AP), als voldoende ervaren. De resultaten laten zien dat de scores voor de kwaltiteit van de supervisie boven de beschouwde normen van dit onderzoek liggen, i.e $\geq 7$ op de 10 -puntsschaal en $\geq 3$ op de 5-puntsschaal. In de twee bestudeerde jaren wordt geen duidelijke verandering waargenomen.

Op de IC-afdelingen blijkt dat de supervisoren van de NICU gemiddeld hoger scoren op de meeste aspecten van supervisie dan hun collega's van de PICU. Uit de resultaten is er geen verklaring af te leiden voor dit verschil. We veronderstellen dat het o.a. te maken heeft met het verschil in patiëntenpopulatie, waarbij op de NICU meer protocollair gewerkt wordt, er minder onverwachte wendingen zijn dan op de PICU en de supervisoren een andere professionele stijl hebben. Uit de geleverde commentaren bleek dat er een sterke voorkeur bestaat voor supervisoren die begrip en geduld tonen.

Op de AP-afdelingen werd de supervisie zeer wisselend beoordeeld, o.a. door de grote hoeveelheid verschillende supervisoren. De items waarop het best werd gescoord, betroffen het creëren van een plezierige leeromgeving en het gestimuleerd worden tot zelfstandig leren en werken naar wat het niveau van de opleiding toelaat (professionele autonomie). Deze 
kwaliteiten blijken ook de belangrijkste aspecten in het bieden van goede supervisie. De algemene opmerkingen, vermeld op de enquêteformulieren, ondersteunen de getallen en maken verder duidelijk dat arts-assistenten het liefst worden benaderd als volwassenen ('adult learners'). Arts-assistenten appreciëren constructieve en op de praktijk gerichte feedback. Zij verafschuwen dominante supervisoren met gebrek aan didactische vaardigheden die er niet zijn op het moment dat je ze nodig hebt. De aspecten van supervisie waarop het minst werd gescoord, waren begeleiding bij het aanleren van praktische en communicatieve vaardigheden en het leren maken van medische beslissingen, rekeninghoudend met de financiële aspecten van de medische zorg.

Een sterke kant van dit onderzoek is dat we gebruik hebben gemaakt van vooraf onderzochte en bewezen betrouwbare vragenlijsten. Hierdoor weten we dat, gezien het feit dat alle supervisoren door minimaal vijf arts-assistenten werden beoordeeld, we een betrouwbaar beeld van de werkelijkheid hebben gekregen (CCTEI). Het feit dat tweemaal hetzelfde onderzoek is uitgevoerd op verschillende tijdstippen en dat de resultaten van de twee meetmomenten zeer vergelijkbaar zijn, bevestigt de betrouwbaarheid van de gebruikte onderzoeksmethode.

Een algemene observatie was dat er bij aanvang een, voor de onderzoekers onverwacht, hoge weerstand bestond bij de stafleden tegen het onderzoek. Men was bang dat er te kritisch beoordeeld zou worden en dat de individuele resultaten algemeen bekend zouden worden. Om deze weerstand enigszins te verminderen hebben we uitleg over de opzet van het onderzoek aan de stafleden gegeven. Er werd duidelijk gesteld dat de resultaten geen consequenties zouden hebben voor de individuele specialist (al is het de bedoeling wel om in volgende jaren de persoonlijke uitkomsten terug te koppelen). Daarnaast hebben we gekozen voor een positieve opzet. Er zijn trofeeën, oorkondes en kadobonnen uitgedeeld aan de supervisoren die het beste scoorden. Er is bewust voor gekozen om in deze eerste fase van dit onderzoek nog geen conclusies te verbinden aan de resultaten van de stafleden die onvoldoende scoorden op één of meerdere aspecten van supervisie.

\section{Conclusie}

Uit dit onderzoek blijkt wat voor arts-assistenten het onderscheid maakt tussen goede en slechte supervisie. Dit wordt bepaald door de mate waarin de volgende aspecten aan- of afwezig zijn:

1. Het bevorderen van een goede communicatie met de arts-assistent (het creëren van een plezierige leeromgeving).

2. Er blijk van geven plezier te hebben in opleiden, m.a.w. 'geduldig en begripvol zijn'.

3. Het aanpassen van de begeleiding aan de ervaring van de arts-assistent.

4. Een goed rolmodel (voorbeeld) zijn.

5. Het stimuleren tot zelfstandig leren; arts-assistenten benaderen als 'volwassen leerling'.

6. Beschikbaarheid.

Voor de supervisie in zijn totaliteit blijkt dat verbetering gewenst is in de benadering van de arts-assistent als volwassen leerling en dat begeleiding aan arts-assistenten nog beter moet aansluiten bij het niveau van de opleiding c.q. de ervaring van de arts-assistent.

Na twee jaar onderzoek concluderen wij dat de grote weerstand tegen dit onderzoek, welke in eerste instantie duidelijk aanwezig was onder de stafleden, sterk is afgenomen: er is meer belangstelling ontstaan bij stafleden voor hun persoonlijke resultaten (functioneren als supervisor) en voor medisch onderwijs in het algemeen. 
Een beperkte interventie in de vorm van het belonen van 'de beste supervisor' heeft geen effect op het verbeteren van de kwaliteit van supervisie. We denken dat de kwaliteit van de opleiding, zoals deze wordt geboden in het EKZ/AMC, alleen kan verbeteren indien supervisoren die consequent onvoldoende scoren hierop aangesproken worden en mogelijk ook als zij zich (bij)scholen in het geven van supervisie. Verder denken wij dat verbetering kan worden behaald door in de huidige opleiding tot medisch specialist aandacht te besteden aan het geven van medisch onderwijs. De arts-assistent van nu is de supervisor van straks! Men dient zich bewust te zijn van het feit dat opleiden een aparte vaardigheid is waarover niet iedere medisch specialist automatisch beschikt.

\section{Dankwoord}

Dank aan prof. dr. A.J.J.A. Scherpbier, directeur Onderwijsinstituut FdG, Universiteit Maastricht, voor zijn kritische opmerkingen op eerdere versies van het manuscript.

\section{Literatuur}

1. McLeod PJ, Harden RM. Clinical teaching strategies for physicians. Med Teach 1985;7:173-89.

2. Lowry S. Teaching the teachers. BMJ 2003;306: 127-30.

3. McLeod PJ, Steinert Y, Meagher T, McLeod A. The ABCs of pedagogy for clinical teachers. Med Educ 2003;37:638-44.

4. Wilkerson L, Irby DM. Strategies for improving teaching practices: a comprehensive approach to faculty development. Acad Med 1998;73:387-96.

5. Kilminster SM, Jolly BC. Effective supervision in clinical practice settings: a literature review. Med Educ 2000;34:827-40.

6. Conn JJ. What can clinical teachers learn from Harry Potter and the Philosopher's Stone? Med Educ 2002;36:1176-81.

7. Cottrell D, Kilminster SM, Jolly BC, Grant J. What is effective supervision and how does it happen? A critical incident study. Med Educ 2002;36:1042-9.
8. Busari JO, Prince KAH, Scherpbier AJJA, Vleuten van der CPM, Essed GGM. How residents perceive their teaching role in the clinical setting - a qualitative study. Med Teach 2002;24(1):57-61.

9. Grant J, Kilminster SM, Jolly BC, Cottrell D. Clinical supervision of SpRs: Where does it happen, when does it happen and is it effective? Med Educ 2003;37:140-8.

10. General medical council. The Doctor as teacher. London: General Medical Council; 1999.

11. Finucane P, Allery LA, Hayes TM. Teachers at a British medical school. Med Teach 1992;14:275-82.

12. Wall D, McAleer S. Teaching the consultant teachers: identifying the core content. Med Educ 2000;34:131-8.

13. Gibson DR, Campbell RM. Promoting effective teaching and learning: hospital consultants identify their needs. Med Educ 2000;34:126-30.

14. Kilminster SM, Jolly BC, Vleuten van der CPM. A framework for effective training of supervisors. Med Teach 2002;24(4):385-9.

15. Hewson MG, Jensen NM. An inventory to improve clinical teaching in the general internal medicine clinic. Med Educ 1990;24:518-27.

16. Copeland LH, Hewson MG. Developing and testing an instrument to measure the effectiveness of clinical teaching in an academic medical center. Acad Med 2000;75:161-6.

\section{De auteurs:}

Dr. J.O. Busari is kinderarts en medisch-onderwijskundige in het Atrium Medisch Centrum te Heerlen.

Drs. P.M. Greidanus is arts-assistent kindergeneeskunde in het Emma Kinderziekenhuis-AMC.

Drs. N.M. Weggelaar is kinderarts. Ten tijde van het onderzoek was zij arts-assistent kindergeneeskunde in het Emma Kinderziekenhuis-AMC.

Drs. I.A.M. Schiering is arts-assistent kindergeneeskunde in het Emma Kinderziekenhuis-AMC.

\section{Correspondentieadres:}

Dr. J.O. Busari, Atrium Medisch Centrum, Henri Dunantstraat 5, Postbus 4446 Heerlen, J.Busari@atriummc.nl.

Belangenconflict: geen gemeld.

Financiële ondersteuning: geen gemeld. 


\section{Summary}

Introduction: Supervision of medical residents in the clinical setting is a key responsibility of attending doctors. Despite its proven importance for medical residents' professional development, most attending doctors are unfamiliar with the principles of medical education. We examined what medical residents perceived to be poor and good supervisory practice.

Method: Two separate standardized questionnaires (2003 \& 2004) were submitted to attending doctors supervising medical residents in the neonatal and pediatric intensive care units and the general pediatric wards of the Department of Pediatrics of the University of Amsterdam, the Netherlands.

Results: The quality of supervision in all departments was rated positively, i.e. 3.57 (sd=0.42) on a five-point scale in the general pediatric wards and $7.21(s d=0.90)$ and $7.49(s d=0.44)$, on a ten-point scale in the pediatric and neonatal intensive care units, respectively. In the general pediatric wards, creating a pleasant learning environment was rated highest $(4.05 ; s d=0.46)$, while clinical decision-making using principles of cost-appropriate care was rated lowest (2.79; sd=0.36). Teaching effective communication skills and coaching on clinical and technical skills were perceived as requiring improvement. The evaluations in 2003 and 2004 yielded no significantly different results.

Discussion and conclusion: The quality of supervision was generally perceived positively. The medical residents desired supervision from patient, collaborative and understanding attending doctors. They preferred being treated as adult learners and enjoyed feedback that is constructive, measured and adapted to their professional needs. There were no significant improvements between 2003 and 2004. There is room for improving the quality of supervision of medical residents. (Busari JO, Greidanus PM, Weggelaar NM, Schiering IAM. Supervision in the medical setting: residents in pediatric wards assess their supervisors. Dutch Journal of Medical Education 2006;25(4):170-179.) 